\title{
Erratum to: The roles of microorganisms in litter decomposition and soil formation
}

\author{
Satoru Hobara • Takashi Osono • Dai Hirose • \\ Kenta Noro $\cdot$ Mitsuru Hirota $\cdot$ Ronald Benner
}

Published online: 28 January 2014

(C) Springer International Publishing Switzerland 2014

\section{Erratum to: Biogeochemistry DOI 10.1007/s10533-013-9912-7}

Table 1 in the original article contained some errors so the correct table is reproduced below. The legend should also read 'Percent remaining (AFDW: ash-free dry weight), $\mathrm{C}$ and $\mathrm{N}$ contents, molar $\mathrm{C}$ to $\mathrm{N}$ ratios, $\mathrm{C}$-normalized yields of total hydrolyzable amino acids (THAA), total hydrolyzable amino sugars (THAS), glucosamine $(\mathrm{GlcN})$, and galactosamine (GalN),

The online version of the original article can be found under doi:10.1007/s10533-013-9912-7.

S. Hobara $(\bowtie) \cdot$ K. Noro

Department of Environmental and Symbiotic Science,

Rakuno Gakuen University, 582 Midorimachi,

Bunkyodai, Ebetsu 069-8501, Japan

e-mail: shobara@rakuno.ac.jp

S. Hobara $\cdot$ R. Benner

Department of Biological Sciences, University of South

Carolina, Columbia, SC 29208, USA

T. Osono

Center for Ecological Research, Kyoto University,

Otsu 520-2113, Japan

D. Hirose

College of Pharmacy, Nihon University, Funabashi,

Chiba 274-8555, Japan

M. Hirota

Graduate School of Life and Environmental Sciences,

University of Tsukuba, Tsukuba 305-8572, Japan
GlcN/GalN ratio, percentages of $\mathrm{C}$ and $\mathrm{N}$ as THAA and THAS, and degradation index (Dl) of decaying litters and soils', addition of the word 'sugars'.

The legend for Table 2 should read 'Molar $\mathrm{C}$ to $\mathrm{N}$ ratios, $\mathrm{C}$-normalized yields of total hydrolyzable amino acids (THAA), total hydrolyzable amino sugars (THAS), glucosamine $(\mathrm{GlcN})$, and galactosamine (GaIN), GlcN/GaIN ratio, and percentages of $\mathrm{C}$ and $\mathrm{N}$ as THAA and THAS of fungi and bacteria', addition of the word 'sugars'. Please also note the spelling change to the word 'Azotobacter' appearing in Table 2. 


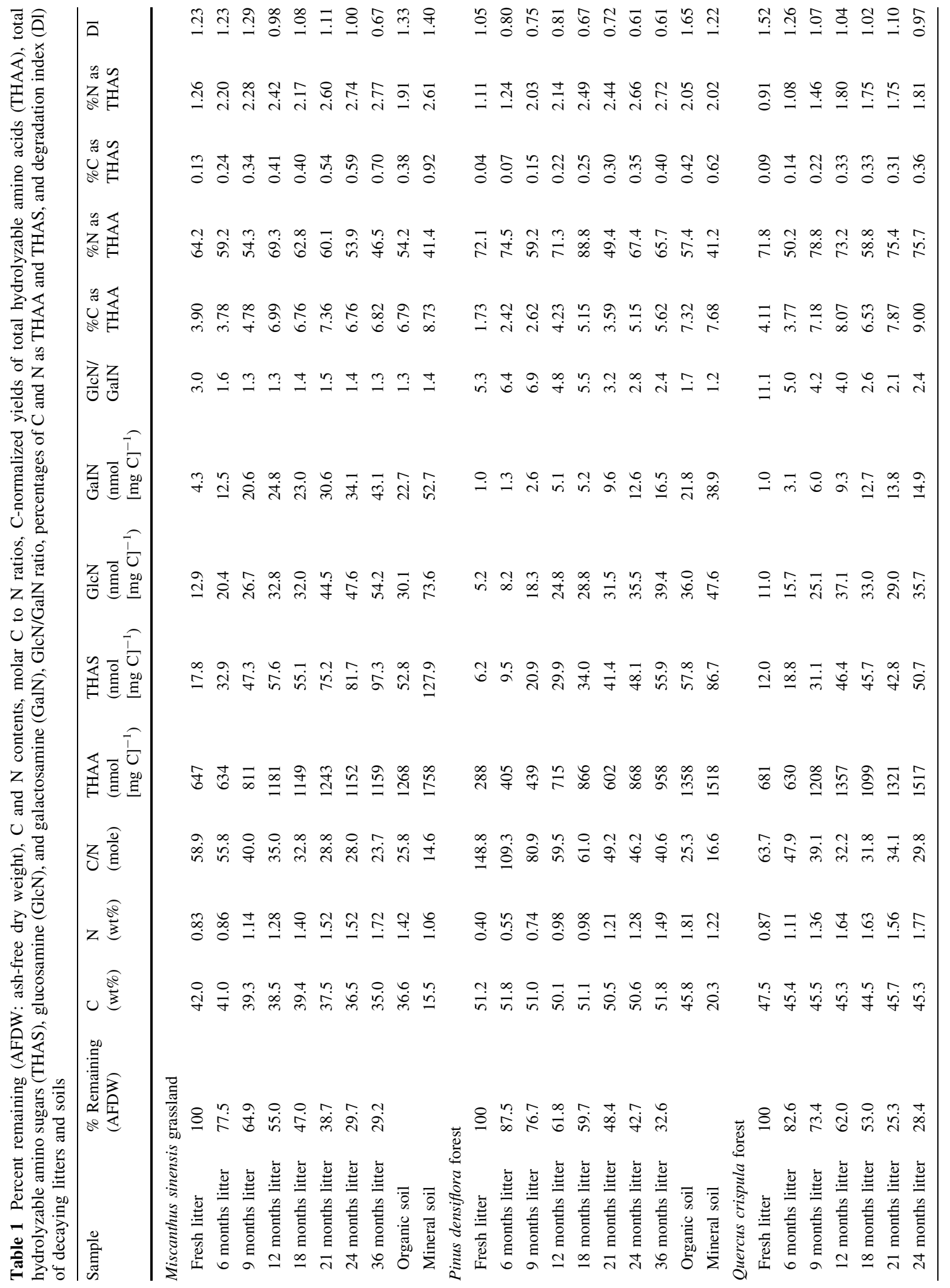




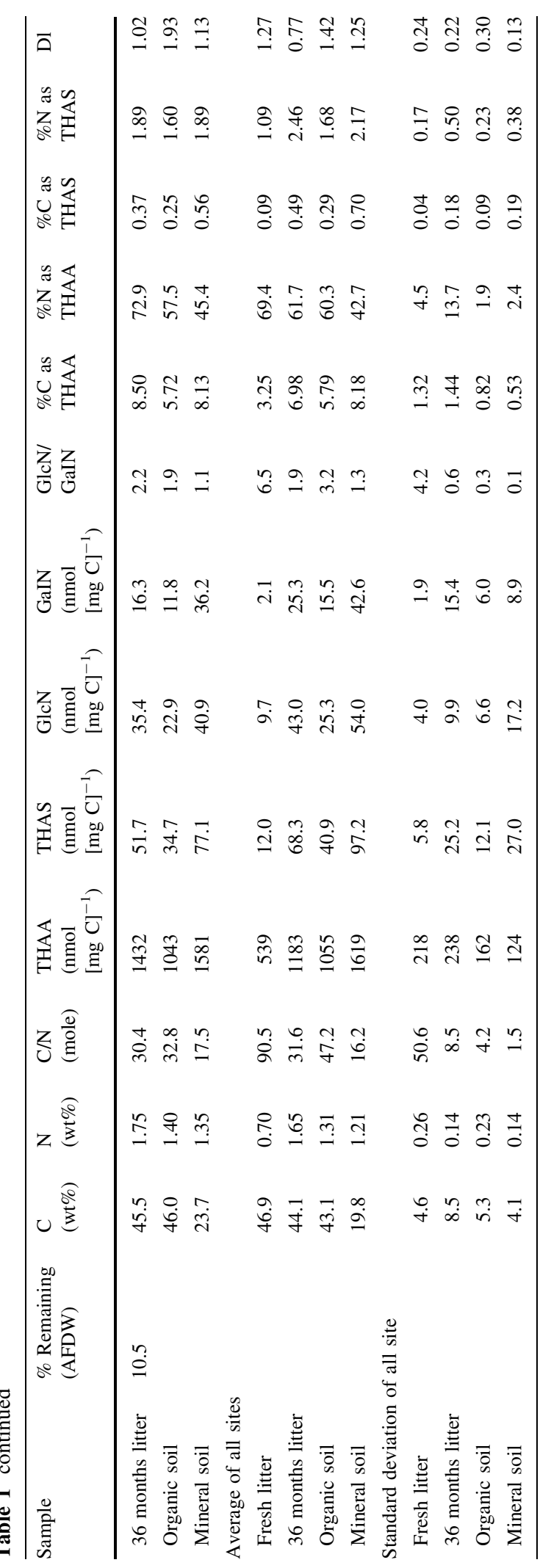

